\title{
Could albumin level explain the higher mortality in hemodialysis patients with pulmonary hypertension?
}

Hugo Hyung Bok Yoo ${ }^{1}$, Luis Cuadrado Martin², Ana Claudia Kochi², Lidiane Silva Rodrigues-Telini², Pasqual Barretti ${ }^{2}$, Jacqueline Teixeira Caramori ${ }^{2}$, Beatriz Bojikian Matsubara ${ }^{3}$, Silméia Garcia Zannati-Bazan ${ }^{3}$, Roberto Jorge da Silva Franco ${ }^{2}$ and Thais Thomaz Queluz ${ }^{* *}$

\begin{abstract}
Background: The pathogenesis of pulmonary hypertension $(\mathrm{PH})$ in hemodialysis is still unclear. The aim of this study was to identify the risk factors associated with the presence of $\mathrm{PH}$ in chronic hemodialysis patients and to verify whether these factors might explain the highest mortality among them.

Methods: We conducted a retrospective study of hemodialysis patients who started treatment from August 2001 to October 2007 and were followed up until April 2011 in a Brazilian referral medical school. According to the results of echocardiography examination, patients were allocated in two groups: those with $\mathrm{PH}$ and those without $\mathrm{PH}$. Clinical parameters, site and type of vascular access, bioimpedance, and laboratorial findings were compared between the groups and a logistic regression model was elaborated. Actuarial survival curves were constructed and hazard risk to death was evaluated by Cox regression analysis.

Results: PH> 35 mmHg was found in 23 (30.6\%) of the 75 patients studied. The groups differed in extracellular water, ventricular thickness, left atrium diameter, and ventricular filling. In a univariate analysis, extracellular water was associated with PH (relative risk $=1.194 ; 95 \% \mathrm{Cl}$ of $1.006-1.416 ; p=0.042$ ); nevertheless, in a multiple model, only left atrium enlargement was independently associated with PH (relative risk $=1.172 ; 95 \% \mathrm{Cl}$ of $1.010-1.359$; $p=0.036$ ). $\mathrm{PH}$ (hazard risk $=3.008 ; 95 \% \mathrm{Cl}$ of $1.285-7.043 ; p=0.011$ ) and age (hazard risk of 1.034 per year of age; $95 \% \mathrm{Cl}$ of $1.000-7.068 ; p=0.047$ ) were significantly associated with mortality in a multiple Cox regression analysis. However, when albumin was taken in account the only statistically significant association was between albumin level and mortality (hazard risk $=0.342$ per $\mathrm{g} / \mathrm{dL} ; 95 \% \mathrm{Cl}$ of $0.119-0.984 ; \mathrm{p}=0.047$ ) while the presence of $\mathrm{PH}$ lost its statistical significance $(p=0.184)$. Mortality was higher in patients with $\mathrm{PH}(47.8 \%$ vs $25 \%)$ who also had a statistically worse survival after the sixth year of follow up.
\end{abstract}

Conclusions: PH in hemodialysis patients is associated with parameters of volume overload that sheds light on its pathophysiology. Mortality is higher in hemodialysis patients with PH and the low albumin level can explain this association.

Keywords: End-stage renal disease, Hemodialysis, Pulmonary hypertension, Prognostic

\footnotetext{
* Correspondence: queluz@fmb.unesp.br

${ }^{1}$ Division of Pulmonology, State University of São Paulo - UNESP, Botucatu

School of Medicine, Botucatu, SP, Brazil

Full list of author information is available at the end of the article
} 


\section{Background}

Pulmonary hypertension (PH) comprises a group of clinical and pathophysiological entities with similar features due to a great variety of underlying conditions $[1,2]$. Chronic renal disease is one of these causes [3] but the pathogenesis of $\mathrm{PH}$ in this group of patients is still unclear. Hemodialysis patients are exposed to continuous pulmonary insults of multifactorial origin, such as hormonal and metabolic derangement associated with end-stage terminal disease, which may induce pulmonary vascular alterations and consequent increased resistance. Besides, high serum level of acute phase reactive protein and cytokines, including IL-1 $\beta$, TNF- $\alpha$ and IL- 6 have been demonstrated in this population suggesting that chronic inflammation might have some role in the pathogenesis of $\mathrm{PH}$ in patients undergoing hemodialysis [4]. On the other side, $\mathrm{PH}$ can cause right ventricular failure with clinical manifestations of systemic venous congestion, pleural effusion, and ascites [1] which might also result in reduced systemic arterial pressure and intradialytic hypotension $[2,5]$. In fact, renal transplantation, by restoring normal renal function, is one of the most effective choices of treatment for $\mathrm{PH}$ in end-stage renal disease patients [6].

$\mathrm{PH}$ has been associated with poor survival in hemodialysis patients [3,6-9]. However, data regarding the prevalence and the influence of others factors that can affect the survival of $\mathrm{PH}$ patients with end-stage renal disease are limited. Hence, the aim of this study is to identify the risk factors associated with the presence of $\mathrm{PH}$ in hemodialysis patients and to verify whether these factors might explain the highest mortality among these patients.

\section{Methods}

We retrospectively collected demographic, clinical, and laboratorial data from the charts of hemodialysis patients of the Division of Nephrology of the University Hospital of the Botucatu School of Medicine, State University of São Paulo, Brazil. Patients had started treatment from August 2001 to October 2007 and were followed up until April 2011. All patients had at least one monthly appointment with their nephrologists at the hospital's clinics.

The inclusion criteria were patients older than 18 years, in the hemodialysis program for over two months, who had a good technical quality echocardiography examination. The exclusion criteria were the presence of ventricular dyskinesias and/or hemodynamically significant valvar disease, alcoholics, psychiatric patients, carriers of hepatic cirrhosis and/or malignant neoplasms.
The Research Ethical Committee of the Botucatu Medical School approved the study and granted a waiver for informed consent $\left(\mathrm{n}^{\circ} 3374 / 09\right)$, since it was only a survey of charts.

Demographic and clinical data (comorbidities, type and location of vascular access and bioimpedance) were recorded. Results of blood tests for hematocrit, C-reactive protein, creatinine, albumin, calcium, phosphorus, and parathyroid hormone levels were also collected. All the results recorded were from exams performed at the beginning of the midweek hemodialysis within at least two weeks before or after the echocardiography study.

Based on this examination, patients were allocated in two groups: $\mathrm{PH}$ group, formed by patients echocardiographycally diagnosed as having $\mathrm{PH}$, and non $\mathrm{PH}$ group, formed by patients with no $\mathrm{PH}$. Clinical and laboratorial findings between these two groups were compared.

Echocardiographic imaging was performed according to a previously standardized technique $[10,11]$ by highly skilled echocardiographers using a Sonos 2000 (Hewlett Packard) equipment attached to a multifrequential 2.5- to $3.5-\mathrm{MHz}$ transducer. The coefficient of variation of echocardiographic measurements in our laboratory was $2.5 \%$. The following data were registered: diameters of the left ventricular (LV) cavity at systole and diastole; thickness of the posterior wall and the septum, both at diastole and systole, left atrium and aorta at systole; systolic volume; early peak of mitral flow velocity ( $\mathrm{E}$ wave); atrial peak filling velocity (A wave). These data were used to calculate the relative thickness of the left ventricle, the left atrium/aorta diameter ratio, the E/A relationship, the LV mass, and LV mass index (LVMI). In case of absence of tricuspid regurgitation, a relationship between time with peek flow/time of right ventricular ejection inferior to 0.3 was defined as $\mathrm{PH}$ [12]. When tricuspid regurgitation was identified with continuous wave Doppler, systolic pulmonary arterial pressure was calculated using a validated equation: $\mathrm{SPAP}=4 \mathrm{X}$ (tricuspid systolic jet $)^{2}+10$ $\mathrm{mmHg}$ (estimated right atrial pressure) [10]. $\mathrm{PH}$ was defined as a systolic pulmonary arterial pressure equal or higher than $35 \mathrm{mmHg}[10,11]$.

Monofrequencial electric bioimpedance $(800 \mu \mathrm{A}$ and $50 \mathrm{kHz}$ ) was performed with Biodynamics 450 device (Biodynamics ${ }^{\circledR}$, USA) after the end of hemodialysis, with the patients in the supine position. Patient's assessments were conducted using a connection between the analyzer to the back of the hand and instep of the subject. Resistance and reactance were measured; phase angle, total body water (TBW), intra (ICW) and extracellular water (ECW) were calculated based on resistance and reactance. Then a microprocessor uses the stored values to 
perform subsequent calculations according to the following equations:

$$
\begin{aligned}
& \text { Phase angle }=\operatorname{arc} \text { tangent }\left(\tan ^{-1}\right) \\
& \text { of reactance } / \text { resistance }[13] ; \\
& \begin{aligned}
\text { Total body water } & =\left(\text { height }{ }^{2} / \text { resistance }\right)+\mathrm{b}(\text { weight }) \\
& +\mathrm{c}(\text { age })+\mathrm{d}[14] ;
\end{aligned}
\end{aligned}
$$

Intracellular water $=\mathrm{a}\left(\right.$ height $\left.^{2}\right)\left(\right.$ reactance $/$ resistance $\left.^{2}\right)$

$$
+\mathrm{b} \text { (weight })+\mathrm{c}(\text { age })+\mathrm{d}[15] \text {; }
$$

Extracellular water $=$ total body water

$$
\text { - intracellular water[15]; }
$$

$$
\text { Leanbodymass }=\mathrm{a}\left(\text { height }^{2}\right)+\mathrm{b}(\text { weight })+\mathrm{c}(\text { age })
$$$$
+\mathrm{d} \text { (resistance) }+\mathrm{e}[13] \text {; }
$$

Fatmass $=$ weight - fat - freemass $[13]$;

Variables a, b, c, d, and e represent constant coefficients calculated by regression analysis in each instance according to references [13-15].

\section{Data analysis}

Normally distributed variables were described as mean and standard deviation and the frequencies as percentage. Variables not normally distributed were described as median and interquartile interval.

The clinical characteristics evaluated at the beginning and at the end of follow-up within groups were compared by paired t-test; the comparisons between $\mathrm{PH}$ group and non-PH group were performed by t-test for unpaired samples, qui-square, or Mann-Whitney test, as appropriate.

Variables with a $>10 \%$ difference between the two groups were selected for multivariate Cox proportional risk regression analysis. Categorical variables were coded as presence (1) or absence (0) to be included in the Cox model. Potential collinearity among variables selected for multiple analysis were tested and if associations were present one of the variables was excluded from the Cox model. Results were considered significant at $\mathrm{P}<0.05$. Three Cox models were elaborated: model 1 , presence of $\mathrm{PH}$; model 2, presence of $\mathrm{PH}$, age, sex, body mass index, presence of smoking, diabetes and/or dyslipidemia, and systolic blood pressure; model 3, the covariates in model 2 and extracellular water. Primary end point was death by any cause. Patients followed until April 2011 who did not reach the end point were censored. Actuarial survival curves were constructed according to the life table method and compared by Greenwod method [16]. A logistic regression model was constructed to evaluate associations between presence of $\mathrm{PH}$ and its risk factors.
Statistical analysis was performed using the Statistical Package for Social Sciences (SPSS) version 12.0 (SPSS, Chicago, IL).

\section{Results}

There were 118 hemodialysis patients eligible for this study, but 43 were excluded for meeting any exclusion criterion. Table 1 shows the clinical characteristics of the 75 patients, 47 males and 28 females, included in the study. Their mean age was $56 \pm 12.7$ years, there were 53 whites, 16 of them in PH group, 20 afro-descendents, seven in $\mathrm{PH}$ group, and two Asiatics, both in non-PH group. There were 18 diabetics, six of them in $\mathrm{PH}$ group, 51 dyslipidemics, 15 of them in $\mathrm{PH}$ group, and 12 smokers, four of them in $\mathrm{PH}$ group. The two groups were not statistically significant different regarding these attributes.

Table 1 also expresses clinical anthropometric and bioimpedance characteristics of groups. $\mathrm{PH}$ group patients presented both more extracellular mass and water. The site and type of vascular access did not differ between groups.

Echocardiographic and laboratorial data are shown in Table 2. The groups differed in ventricular thickness, left atrium diameter, and early systolic peak of ventricular filling.

The associations of $\mathrm{PH}$ with left ventricular hypertrophy, diastolic dysfunction, and volume status were assessed by logistic regression. Firstly, in an univariate analysis, ECW was statistically associated with PH (relative risk of 1.194; 95\% confidence interval of 1.006 1.416; $\mathrm{p}=0.042$ ). Secondly, including left atrium this variable was statistically associated with the presence of $\mathrm{PH}$ (relative risk of 1.216; 95\% confidence interval of 1.057 - 1.398; $\mathrm{p}=0.006)$ and ECW lost its significance $(p=0.303)$. In subsequent models, in which were successively included diastolic filing of left ventricle, albumin level, and posterior wall thickness only left atrium maintained statistically significant association with $\mathrm{PH}$ (relative risk of 1.172; 95\% confidence interval of $1.010-$ 1.359; $\mathrm{p}=0.036$ ).

Among the 23 patients with $\mathrm{PH}$ there were 11 deaths $(47.8 \%)$ while among the 52 patients without $\mathrm{PH}$ there were 13 deaths $(25 \%)$. Survival table curves concerning the presence or absence of $\mathrm{PH}$ are expressed in Figure 1. $\mathrm{PH}$ patients had a statistically worse survival after the sixth year of follow up.

Cox regression analysis, which included variables with $\mathrm{p}<0.1$ between groups, revealed a statistically significant association only between albumin levels and mortality (Table 3).

The Cox model 1, constructed only with the presence of $\mathrm{PH}$, demonstrated statistically significant association between $\mathrm{PH}$ and mortality (hazard risk of 2.438; 95\% confidence interval of $1.128-5.266 ; \mathrm{p}=0.023)$. The 
Table 1 Clinical and bioimpedance data in groups of hemodialysis patients with and without pulmonary hypertension

\begin{tabular}{|c|c|c|c|}
\hline & Pulmonary Hypertension $(n=23)$ & No Pulmonary Hypertension $(n=52)$ & $\mathrm{p}$ \\
\hline Age (years) & $59 \pm 11.2$ & $55 \pm 13.3$ & 0.189 \\
\hline Male/Female & $16 /$ & $29 /$ & 0.385 \\
\hline White/non White & $9 / 14$ & $18 / 34$ & 0.909 \\
\hline BMI (Kg/m2) & $24.9 \pm 3.86$ & $24.4 \pm 5.08$ & 0.695 \\
\hline Vascular access & & & 0.777 \\
\hline Radial autologous & 18 & 34 & \\
\hline Brachial autologous & 1 & 5 & \\
\hline Radial graft & 1 & 5 & \\
\hline Femoral graft & 2 & 4 & \\
\hline Catheter & 1 & 4 & \\
\hline IWG (kg) & $2.2(2.0-3.2)$ & $2.8(2.2-3.4)$ & 0.229 \\
\hline $\mathrm{SBP}(\mathrm{mm} \mathrm{Hg})$ & $142 \pm 17.2$ & $147 \pm 14.0$ & 0.221 \\
\hline $\mathrm{DBP}(\mathrm{mm} \mathrm{Hg})$ & $86 \pm 9.16$ & $89 \pm 8.35$ & 0.131 \\
\hline Phase angle (degree) & $6.3 \pm 1.2$ & $6.6 \pm 1.2$ & 0.243 \\
\hline Capacitance & $619.0 \pm 194.8$ & $635.2 \pm 149.3$ & 0.701 \\
\hline Resistance & $582.3 \pm 104.1$ & $591.8 \pm 87.9$ & 0.691 \\
\hline Reactance & $62.8 \pm 10.7$ & $69.6 \pm 16.7$ & 0.087 \\
\hline Cellular mass (kg) & $22.2 \pm 5.9$ & $20.5 \pm 4.7$ & 0.197 \\
\hline Extracellular mass (kg) & $25.8 \pm 4.9$ & $22.8 \pm 4.9$ & 0.019 \\
\hline LM (kg) & $48 \pm 10.3$ & $43.3 \pm 9.0$ & 0.055 \\
\hline $\mathrm{FM}(\mathrm{kg})$ & $20.7 \pm 8.5$ & $20.0 \pm 8.7$ & 0.737 \\
\hline ICW (I) & $19.1 \pm 5.0$ & $17.6 \pm 3.7$ & 0.175 \\
\hline ECW (I) & $15.7 \pm 2.6$ & $14.0 \pm 3.2$ & 0.032 \\
\hline TBW (I) & $0.857 \pm 0.184$ & $0.811 \pm 0.176$ & 0.317 \\
\hline ECW/TBW (\%) & $34.8 \pm 6.9$ & $31.668 \pm 6.0$ & 0.055 \\
\hline
\end{tabular}

BMI: body mass index; IWG: interdialytic weight gain; SBP: systolic blood pressure; DBP: diastolic blood pressure; LM: lean body mass; FM: fat mass; ICW: intracellular water; $E C W$ : extracellular water; TBW: total body water.

model 2, performed with presence of $\mathrm{PH}$, age, sex, body mass index, presence of smoking, diabetes mellitus and/ or dyslipidemia, and systolic blood pressure, revealed a statistically significant association between both $\mathrm{PH}$ and mortality (hazard risk of 3.008; 95\% confidence interval of $1.285-7.043 ; \mathrm{p}=0.011$ ) and age and mortality (hazard risk of 1.034 per year of age; $95 \%$ confidence interval of $1.000-7.068 ; \mathrm{p}=0.047)$. The model 3, elaborated with all these covariates and extracellular water, showed a statistically significant association between $\mathrm{PH}$ and mortality (hazard risk of $3.164 ; 95 \%$ confidence interval of $1.267-7.900 ; \mathrm{p}=0.014$ ) and a marginally association between age and mortality (hazard risk of 1.034 per year of age; $95 \%$ confidence interval of 0.999 - 1.071; $\mathrm{p}=0.055$ ). In this last model, any other covariate presented significant association with mortality. When $\mathrm{PH}$ was included with albumin, only albumin retained statistical significance (hazard risk of 0.342 per $\mathrm{mg} / \mathrm{dL} ; 95 \%$ confidence interval of $0.119-0.984 ; \mathrm{p}=0.047$ ) while the presence of $\mathrm{PH}$ lost its statistical significance $(\mathrm{p}=0.184)$.

\section{Discussion}

In this cohort of 75 hemodialysis patients, followed up until 10 years, the frequency of $\mathrm{PH}$, evaluated by echocardiography, was $30.6 \%$. As showed in other studies [3,6-9] the presence of $\mathrm{PH}$ was associated with a poor prognosis and this fact is accentuated at six years of follow-up. Hemodialysis patients with $\mathrm{PH}$ presented differences in cardiac morphology, clinical, and biochemical characteristics when compared with no-PH patients. Cox regression analysis, which included confounding variables, indicated that the effect of $\mathrm{PH}$ on mortality is independent of age, sex, body mass index, smoking, diabetes mellitus, dyslipidemia, systolic blood pressure and extracellular water. However, when albumin is included in a model with $\mathrm{PH}$, only albumin retains statistical significance while $\mathrm{PH}$ lost its significance as a predictor of mortality. Hence, as lower is the albumin level as higher is the mortality. Therefore, in the current study, the prognostic impact of $\mathrm{PH}$ on hemodialysis patients appears to be mediated by lower albumin levels. 
Table 2 Echocardiographic and laboratorial data in groups of hemodialysis patients with and without pulmonary hypertension

\begin{tabular}{|c|c|c|c|}
\hline & Pulmonary Hypertension $(n=23)$ & No pulmonary Hypertension $(n=52)$ & $\mathrm{p}$ \\
\hline LVIDD (mm) & $48.6 \pm 5.86$ & $49.0 \pm 6.57$ & 0.810 \\
\hline PWT (mm) & $12.5 \pm 1.72$ & $11.5 \pm 1.76$ & 0.016 \\
\hline IVST (mm) & $13.0 \pm 1.74$ & $11.9 \pm 2.26$ & 0.042 \\
\hline LVRWT & $0.53 \pm 0.109$ & $0.49 \pm 0.111$ & 0.087 \\
\hline LVM (g) & $309 \pm 75.5$ & $277 \pm 78.8$ & 0.101 \\
\hline LVMI $\left(\mathrm{g} / \mathrm{m}^{2.7}\right)$ & $81.7 \pm 23.51$ & $78.4 \pm 23.10$ & 0.575 \\
\hline $\mathrm{LA}(\mathrm{mm})$ & $46.2 \pm 4.29$ & $41.9 \pm 5.68$ & 0.002 \\
\hline $\mathrm{AO}(\mathrm{mm})$ & $34.1 \pm 4.59$ & $32.5 \pm 3.47$ & 0.102 \\
\hline LA/AO & $1.4 \pm 0.21$ & $1.3 \pm 0.20$ & 0.140 \\
\hline $\mathrm{E} \mathrm{cm} / \mathrm{s}$ & $81.1 \pm 28.57$ & $65.7 \pm 28.53$ & 0.042 \\
\hline $\mathrm{A} \mathrm{cm} / \mathrm{s}$ & $87.3 \pm 23.88$ & $81.0 \pm 18.71$ & 0.256 \\
\hline $\mathrm{E} / \mathrm{A}$ & $0.79(0.70-0.94)$ & $0.74(0.55-0.94)$ & 0.224 \\
\hline PTH $(p g / m l)$ & $241(117-491)$ & $257(128-481)$ & 0.726 \\
\hline Creatinine (mg/dl) & $10.7 \pm 3.16$ & $10.9 \pm 3.07$ & 0.811 \\
\hline Albumin (g/dl) & $3.6 \pm 0.36$ & $3.8 \pm 0.41$ & 0.082 \\
\hline Calcium (mg/dl) & $9.1 \pm 0.80$ & $9.0 \pm 0.72$ & 0.756 \\
\hline Phosphorus (mg/dl) & $4.6 \pm 1.74$ & $5.3 \pm 1.57$ & 0.134 \\
\hline $\mathrm{Ca} \times \mathrm{P}$ & $42.5 \pm 16.94$ & $47.3 \pm 14.33$ & 0.204 \\
\hline $\mathrm{CRP}(\mathrm{mg} / \mathrm{dL})$ & $0.8(0.20-1.27)$ & $0.5(0.10-1.20)$ & 0.633 \\
\hline $\mathrm{Ht}(\%)$ & $33.6 \pm 5.54$ & $33.2 \pm 4.31$ & 0.707 \\
\hline
\end{tabular}

LVIDD: left ventricular internal diastolic dimension; PWT: posterior wall thickness; IVST: interventricular septum thickness; $L V R W T$ : left ventricular relative wall thickness; LVM: left ventricular mass; LVMI: left ventricular mass index; LA: left atrium; $A O$ : aorta; $E$ : early peak diastolic flow; $A$ : atrial peak diastolic flow; PTH: parathyroid hormone; $C a \times P$ : calcium phosphorus product; $C R P$ : C-reactive protein; $H t$ : hematocrit.

The studies that pointed out to the scanty prognosis in hemodialysis patients with $\mathrm{PH}$ did not evaluated possible factors, such as albumin or volemic status, that could interfere on mortality in hemodialysis [3,17-21]. Ygla et al [8] showed, by multiple analyses, that besides age, $\mathrm{PH}$ was an independent predictor of prognosis, what is in accord with our findings, but their analysis was not adjusted to any biochemical markers of prognosis.

In the present study, $\mathrm{PH}$ was associated with markers of volume overload: large left atrium and increased extracellular water. In a multiple logistic regression analysis, only left atrium diameter retained statistically

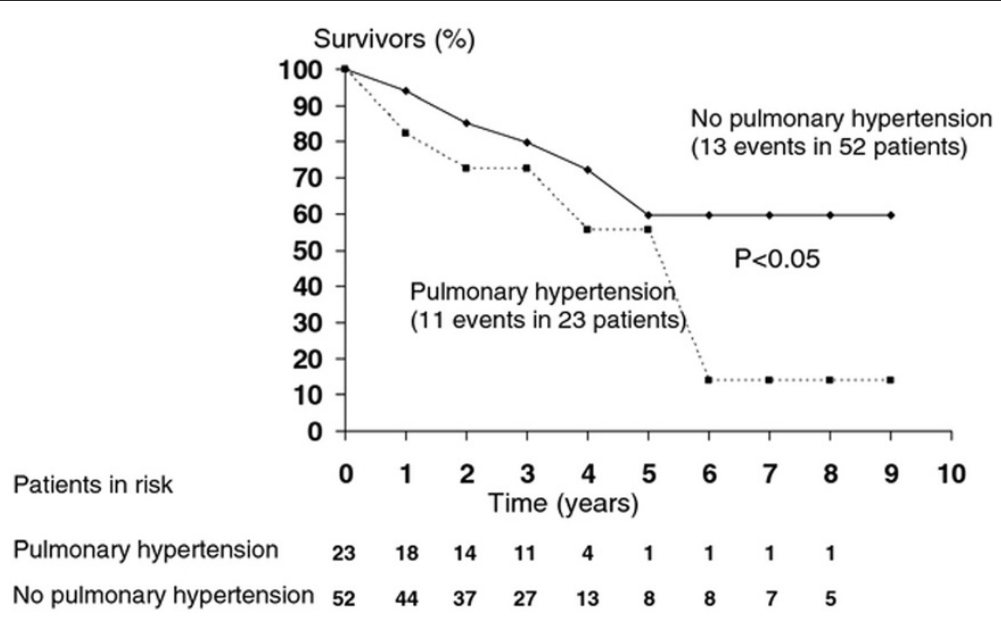

Figure 1 Mortality associated with pulmonary hypertension in hemodialysis patients. 
Table 3 Cox regression: all mortality causes in hemodialysis patients

\begin{tabular}{|c|c|c|c|c|}
\hline & \multirow{2}{*}{$\begin{array}{l}\text { Hazard } \\
\text { ratio }\end{array}$} & \multicolumn{2}{|c|}{$95.0 \% \mathrm{Cl}$ for $\mathrm{HR}$} & \multirow[t]{2}{*}{$\mathrm{p}$-value } \\
\hline & & Lower & Upper & \\
\hline Albumin (g/dL) & 0.117 & 0.019 & 0.714 & 0.020 \\
\hline Relative wall thickness & 0.039 & 0.000 & $3.78 \times 10^{2}$ & 0.488 \\
\hline Posterior wall (mm) & 1.515 & 0.841 & 2.730 & 0.167 \\
\hline Interventricular septum (mm) & 1.055 & 0.587 & 1.898 & 0.858 \\
\hline$\underline{\text { Left atrium }(\mathrm{mm})}$ & 0.925 & 0.806 & 1.060 & 0.261 \\
\hline Early peak diastolic (cm/s) & 0.992 & 0.971 & 1.013 & 0.435 \\
\hline $\mathrm{PH}$ (presence/absence) & 1.734 & 0.555 & 5.415 & 0.344 \\
\hline ECW/TBW & $2.1 \times 10^{3}$ & 0.001 & $4.1 \times 10^{9}$ & 0.299 \\
\hline Intracellular water $(\mathrm{L})$ & 0.817 & 0.582 & 1.146 & 0.241 \\
\hline Height (m) & 0.996 & 0.918 & 1.081 & 0.932 \\
\hline Reactance $(\Omega)$ & 0.991 & 0.937 & 1.048 & 0.755 \\
\hline
\end{tabular}

PH: pulmonary hypertension; ECW/TBW: extracellular water/total body water.

significant association with $\mathrm{PH}$. It is of note that there is a correlation statistically significant between ECF/TBW and left atrium diameter $(\mathrm{r}=0.33 ; \mathrm{p}<0.01)$ (data not shown). Thus, we hypothesize that volume overload can be important in the physiopathogenesis of $\mathrm{PH}$ observed in hemodialysis patients. Corroborating this idea, there are studies that demonstrate higher cardiac output and lower hemoglobin level in $\mathrm{PH}$ hemodialysis patients [1719]. In addition, a recent study by Agarwal [9] showed that left atrial diameter is strongly associated with $\mathrm{PH}$ in hemodialysis patients, fact that might reflect chronic volume overload. It is noteworthy that our results also suggest that if right cardiac catheterization had been carried out it possibly would reveal a post-capillary $\mathrm{PH}$ which is known as an important risk factor for poor outcome of patients with left heart disease [22].

Although some authors have demonstrated that site and type of vascular access have influence on pulmonary pressure [17-19], we did not find differences regarding to this matter. Also, the association of mineral bone renal disease markers with $\mathrm{PH}$ was not observed in the current study differing from Havlucu et al [17] who found increased of parathyroid hormone levels in patients with elevated systolic pulmonary arterial pressure. On the contrary, in accordance with other authors $[9,20,21]$ our $\mathrm{PH}$ and no-PH groups were homogeneous concerning calcium, phosphorus, and parathyroid hormone levels.

The tendency to lower albumin level in $\mathrm{PH}$ group could be explained by two mechanisms: hemodilution or inflammation. PH group presented markers of overload volume, such as higher extracellular volume, evaluated by bioimpedance, and larger left atrium, while the C-reactive protein was similar in both groups. As C-reactive protein levels were not different between groups, we can suppose that albumin was not decreased by microinflammation; consequently, dilution is the strongest hypothesis to explain the lower albumin levels in $\mathrm{PH}$ group. Besides, we stress a statistically significant correlation between ECF/ TBW and albumin $(\mathrm{r}=0.41 \mathrm{p}<0.01)$ (data not shown). Therefore, these findings point out to hemodilution as the presumable mechanism to explain the propensity to lower albumin level in $\mathrm{PH}$ group. Thus, we speculate that volume overload participates in the genesis of increased pulmonary arterial pressure in hemodialysis patients. This physiopathological mechanism of $\mathrm{PH}$ might be a peculiarity of chronic kidney disease.

Some limitations must be addressed in the present study. Firstly, it is the small number of patients in our series, but our results encourage its reproduction to confirm these results in other series. Secondly, PH was identified only by echocardiography and not confirmed by right cardiac catheterization. Nevertheless, for ethical reasons, invasive exams for research objectives are not justified. In fact, none of previous studies on $\mathrm{PH}$ in hemodialysis patients evaluated pulmonary arterial pressure invasively. Thirdly, the vascular hemodialysis access flux was not measured; however the local and type of access were similar and did not differ statistically between the two groups.

\section{Conclusion}

$\mathrm{PH}$ in hemodialysis patients is associated with parameters of volume overload that sheds light on its pathophysiology. Mortality in hemodialysis patients is higher in $\mathrm{PH}$ patients, but in a multiple analysis, low level of albumin could explain this association. For the time being, our results suggest that considering the scanty prognostic of hemodialysis patients with $\mathrm{PH}$, strict attention should be taken to avoid volume overload in this population. Perhaps, daily or extended dialysis might help to reach this aim.

\section{Competing interests}

The authors declare that they have no competing interests.

\section{Authors' contributions}

HHBY, LCM, LST-R, TTQ: conceived and designed the study, interpreted the content analysis, and drafted the manuscript. SGZ-B, BBM: carried out the echocardiography, interpreted the content analysis, and drafted the manuscript. ACK, PB JTC, RJSF: carried out the follow-up, interpreted the content analysis, and drafted the manuscript. All authors read and approved the final manuscript

\section{Acknowledgements}

This work was supported by University Hospital of the Botucatu School of Medicine, UNESP.

\section{Author details}

${ }^{1}$ Division of Pulmonology, State University of São Paulo - UNESP, Botucatu School of Medicine, Botucatu, SP, Brazil. ${ }^{2}$ Division of Nephrology, State University of São Paulo - UNESP, Botucatu School of Medicine, Botucatu, SP, Brazil. ${ }^{3}$ Division of Cardiology, State University of São Paulo - UNESP Botucatu School of Medicine, Botucatu, SP, Brazil. 
Received: 21 November 2011 Accepted: 31 July 2012

Published: 6 August 2012

\section{References}

1. Runo JR, Loyd JE: Primary pulmonary hypertension. Lancet 2003, 361:1533-1544.

2. Rich S: Primary pulmonary hypertension. Prog Cardiovasc Dis 1998, 31:205-238.

3. Yigla M, Dabbah S, Azzam ZS, Rubin AH, Reisner SA: Background disease in 671 patients with moderate to severe pulmonary hypertension. Isr Med Assoc J 2000, 2:684-689.

4. Yu TM, Chen YH, Hsu JY, Sun CS, Chuang YW, Chen $\mathrm{CH}$, Wu MJ, Cheng $\mathrm{CH}_{\text {, }}$ Shu $\mathrm{KH}$ : Systemic inflammation is associated with pulmonary hypertension in patients undergoing haemodialysis. Nephrol Dial Transplant 2009, 24:1946-1951.

5. Ifudu O: Care of patients undergoing hemodialysis. N Engl J Med 1998, 339:1054-1062.

6. Bozbas SS, Akcay S, Altin C, Bozbas H, Karacaglar E, Kanyilmaz S, Sayin B, Muderrisoglu $\mathrm{H}$, Haberal $\mathrm{M}$ : Pulmonary hypertension in patients with endstage renal disease undergoing renal transplantation. Transplant Proc 2009, 41:2753-2756.

7. Yigla M, Nakhoul F, Sabag A, Tov N, Gorevich B, Abassi Z, Reisner SA Pulmonary hypertension in patients with end-stage renal disease. Chest 2003, 123:1577-1582.

8. Yigla M, Fruchter $O$, Aharonson D, Yanay N, Reisner SA, Lewin M, Nakhoul F: Pulmonary hypertension is an independent predictor of mortality in hemodialysis patients. Kidney Int 2009, 75:969-975.

9. Agarwal R: Prevalence, determinants and prognosis of pulmonary hypertension among hemodialysis patients. Nephrol Dial Transplant 2012, Epub ahead of print

10. Quinones MA, Otto CM, Stoddard M, Waggoner A, Zoghbi WA: Recommendations for quantification of Doppler echocardiography: a report from the Doppler quantification task force of the nomenclature and standards committee of the American society of Echocardiography. J Am Soc Echocardiogr 2002, 15:167-184.

11. Lang RM, Bierig M, Devereux RB, Flachskampf FA, Foster E, Pellikka PA, Picard MH, Roman MJ, Seward J, Shanewise JS, Solomon SD, Spencer KT, Sutton MS, Stewart WJ, Chamber Quantification Writing Group, American Society of Echocardiography's Guidelines and Standards Committee, European Association of Echocardiography: Recommendations for chamber quantification: a report from the American Society of Echocardiography's Guidelines and Standards Committee and the Chamber Quantification Writing Group, developed in conjunction with the European Association of Echocardiography, a branch of the European Society of Cardiology. J Am Soc Echocardiogr 2005, 18:1440-1463.

12. Kitabatake A, Inoue M, Asao M, Masuyama T, Tanouchi J, Morita T, Mishima M, Uematsu M, Shimazu T, Hori M, Abe H: Noninvasive evaluation of pulmonary hypertension by a pulsed Doppler technique. Circulation 1983, 68:302-309.

13. Biodynamics products information; http://www.biodyncorp.com/tools/450/ calculations.html. Accessed on 08/02/2012.

14. Kushner RF, Schoeller DA: Estimation of total body water by bioelectrical impedance analysis. Am J Clin Nutr 1986, 44:417-424.

15. Cohn SH, Vaswani AN, Yasumura S, Yuen K, Ellis KJ: Assessment of cellular mass and lean body mass by noninvasive nuclear techniques. J Lab Clin Med 1985, 105:305-311.

16. Greenwod M: The errors of sampling of the survivorship tables. Appendix 1 in Reports on public health and statistical subjects, No 33. London: His Majesty's Stationery Office; 1926.

17. Havlucu Y, Kursat S, Ekmekci C, Celik P, Serter S, Bayturan O, Dinc G: Pulmonary hypertension in patients with chronic renal failure. Respiration 2007, 74:503-510.

18. Tarrass F, Benjelloun M, Hachim K, Benghanem MG, Ramdani B: Pulmonary hypertension in patients with end-stage renal disease. Indian J Nephrol 2005, 15:223-226.

19. Nakhoul F, Yigla M, Gilman R, Reisner SA, Abassi Z: The pathogenesis of pulmonary hypertension in haemodialysis patients via arterio-venous access. Nephrol Dial Transplant 2005, 20:1686-1692.
20. Amin M, Fawzy A, Hamid MA, Elhendy A: Pulmonary hypertension in patients with chronic renal failure. Role of parathyroid hormone and pulmonary artery calcifications. Chest 2003, 124:2093-2097.

21. Abdelwhab S, Elshinnawy S: Pulmonary hypertension in chronic renal failure patients. Am J Nephrol 2008, 28:990-997.

22. Khush KK, Tasissa G, Javed Butler J, McGlothlin D, De Marco T, for the ESCAPE Investigators: Effect of pulmonary hypertension on clinical outcomes in advanced heart failure: Analysis of the Evaluation Study of Congestive Heart Failure and Pulmonary Artery Catheterization Effectiveness (ESCAPE) database. Am Heart J 2009, 157:1026-1034.

doi:10.1186/1471-2369-13-80

Cite this article as: Yoo et al:: Could albumin level explain the higher mortality in hemodialysis patients with pulmonary hypertension?. BMC Nephrology 2012 13:80.

\section{Submit your next manuscript to BioMed Central and take full advantage of:}

- Convenient online submission

- Thorough peer review

- No space constraints or color figure charges

- Immediate publication on acceptance

- Inclusion in PubMed, CAS, Scopus and Google Scholar

- Research which is freely available for redistribution 